\title{
Tackling the stacking disorder of melon-structure elucidation in a semicrystalline material $\dagger$
}

\author{
Lena Seyfarth, ${ }^{a}$ Jan Seyfarth, ${ }^{a}$ Bettina V. Lotsch, ${ }^{b}$ Wolfgang Schnick ${ }^{b}$ and \\ Jürgen Senker*a
}

Received 24th September 2009, Accepted 20th November 2009

First published as an Advance Article on the web 15th January 2010

DOI: $10.1039 / \mathrm{b919918g}$

In this work we tackle the stacking disorder of melon, a layered carbon imide amide polymer with the ideal composition $\left(\mathrm{C}_{6} \mathrm{~N}_{7}(\mathrm{NH})\left(\mathrm{NH}_{2}\right)\right)$. Although its existence has been postulated since 1834 the structure of individual melon layers could only recently be solved via electron diffraction and high-resolution ${ }^{15} \mathrm{~N}$ solid-state NMR spectroscopy. With only weak van der Waals interactions between neighboring layers its long range stacking order is poorly defined preventing an efficient use of diffraction techniques. We, therefore, rely on a combination of solid-sate NMR experiments and force field calculations. The key information is obtained based on heteronuclear $\left({ }^{1} \mathrm{H}-{ }^{13} \mathrm{C}\right)$ and homonuclear $\left({ }^{1} \mathrm{H}-{ }^{1} \mathrm{H}\right)$ second moments $M_{2}$ acquired from ${ }^{1} \mathrm{H}-{ }^{13} \mathrm{C}$ cross polarization experiments. To allow for an interpretation of the polarization transfer rates the resonances in the ${ }^{13} \mathrm{C}$ MAS spectra have to be assigned and the hydrogen atoms have to be located. The assignment was performed using a two-dimensional ${ }^{15} \mathrm{~N}-{ }^{13} \mathrm{C} i D C P$ experiment. For the determination of the position of the hydrogen atoms $\mathrm{NH}$ and $\mathrm{HH}$ distances were measured via ${ }^{1} \mathrm{H}-{ }^{15} \mathrm{~N}$ Lee-Goldburg $\mathrm{CP}$ and ${ }^{1} \mathrm{H}-{ }^{1} \mathrm{H}$ double-quantum build-up curves, respectively. Furthermore, the homogeneity of the material under examination was investigated exploiting ${ }^{15} \mathrm{~N}$ spin-diffusion. Based on force field methods 256 structure models with varying lateral arrangements between neighboring layers were created. For each model the $M_{2}$ were calculated allowing them to be ranked by comparing calculated and measured $M_{2}$ as well as via their force field energies. This allows the creation of markedly structured hypersurfaces with two distinctly favored shift vectors for the displacement of neighboring layers.

\section{Introduction}

During the last two decades scientific research on carbon nitride materials underwent a renaissance sparked by theoretical calculations predicting a $3 \mathrm{D}$ form of carbon nitride to be harder than diamond. ${ }^{1,2}$ Since then, a plethora of structure models were developed, based either on 3D networks or graphite-like layered structures. ${ }^{3}$ While for the latter, both triazine $\left(\mathrm{C}_{3} \mathrm{~N}_{3}\right)$ and heptazine $\left(\mathrm{C}_{6} \mathrm{~N}_{9}\right)$ subunits have been put forward as elementary building blocks, evidence for the heptazine model keeps accumulating. ${ }^{4,5}$ Structure elucidation of carbon nitride materials allows for the design of optimized synthesis protocols and is, arguably, the key to their macroscopic properties. Recently, analogies have been revealed between the first continuous 2D carbon nitride network and crystalline triazine-based covalent organic frameworks, dubbed "CTFs". 6,7 The framework topology of poly(heptazine imide), $\left(\mathrm{C}_{6} \mathrm{~N}_{7}\right)_{2}(\mathrm{NH})_{3} \cdot \mathrm{C}_{3} \mathrm{~N}_{3}\left(\mathrm{NH}_{2}\right)_{3}$, though featuring "closed" pores occupied by the template melamine, bodes well for the

\footnotetext{
${ }^{a}$ Anorganische Chemie I, Universität Bayreuth, Universitätsstrasse 30, 95440 Bayreuth, Germany.E-mail: juergen.senker@uni-bayreuth.de

${ }^{b}$ Department Chemie und Biochemie, Ludwig-Maximilians-Universität, Butenandtstrasse 5-13 (D), 81377 München, Germany

$\dagger$ Dedicated to Prof. Dr h. c. Martin Jansen on the occasion of his 65 th birthday.
}

templated synthesis of novel, highly porous carbon nitride architectures with tailor-made properties.

Despite the recent progress made towards highly condensed $\mathrm{CN}_{x}$ materials, experimental access to carbon nitrides remains a challenge due to their metastability with respect to the formation of graphite and nitrogen. ${ }^{3,8}$ Since most synthetic routes invoke the pyrolysis of molecular precursors, ${ }^{9-12}$ moreover, the incorporation of additional hetero atoms or hydrogen can hardly be prevented. This was demonstrated recently by Thomas et al. who reported on the synthesis of a microcrystalline, largely hydrogen free graphitic carbon nitride-type material by ionothermal treatment of dicyandiamide. ${ }^{13}$ Nevertheless, reports on promising properties and applications of carbon nitride materials abound in the literature. These imply mechanical hardness and elasticity, ${ }^{1,3,14,15}$ fire-retarding and field-emission properties, ${ }^{16}$ as well as potential in energy conversion, ${ }^{3,14}$ hydrogen ${ }^{17}$ and $\mathrm{Li}^{18}$ storage, in solar cells, ${ }^{19}$ as humidity and gas sensors ${ }^{20}$ as well as semiconductors. ${ }^{18,21}$ Along these lines, a recent break-through was achieved by the use of polymeric carbon nitride as an efficient and inexpensive photocatalyst for water splitting. ${ }^{22}$ Moreover, the same material was demonstrated to be active as a metal-free heterogeneous catalyst in Friedel-Crafts reactions, the activation of $\mathrm{CO}_{2}$ and in the cyclotrimerisation of triple bonds. ${ }^{23-26}$

In these applications mainly layered materials are employed which are prepared as bulk materials, ${ }^{15,27-35}$ as films, ${ }^{16,17,19,20,36-39}$ 
as nano- or mesoporous samples, ${ }^{14,23,26,33,40}$ and as nanotubes. ${ }^{18,41}$ For nearly all cases hydrogen contents well above $1.6 \mathrm{wt}-\%$ were observed, which indicates the presence of oligo- or polymeric melon-type materials rather than of binary carbon nitride. , 29,30,35,42-44 $^{\text {The acquisition of accurate }}$ data beyond stoichiometry and composition remains largely elusive due to an inherent poor crystallinity and a high degree of disorder. X-ray powder patterns usually indicate a pronounced stacking disorder of neighboring layers with an interlayer distance amounting to about $3.2 \AA .4,9,13,23,42$ Besides X-ray diffraction techniques, ${ }^{15,27-31,34,40,42-44}$ infrared (IR) and Raman spectroscopy ${ }^{15,20,27,28,32,33,40,45}$ as well as X-ray photoelectron spectroscopy (XPS) ${ }^{16,19,26,29,30}$ are the most commonly employed characterization techniques. As these mostly probe the local environment rather than intermediate or long range properties, no information about the stacking disorder of melon-type materials have been obtained. However, real world applications of carbon nitrides necessitate an understanding of the structure-property relationship and mechanistic aspects of their catalytic performance, both of which are intrinsically linked to their 3D architecture.

The current work is thus dedicated to unravelling the 3D arrangement of neighboring layers in highly condensed graphitic carbon nitride materials. Due to the inherent disorder we rely on a combination of quantitative multinuclear solid-state NMR spectroscopic experiments and chemical modeling based on force fields. Within the restraints of the diffraction data the force field calculations allow for a fast buildup of structure models and the determination of homo- and heteronuclear second moments provides a straightforward and accurate verification. ${ }^{46}$ As a case study we used Liebig's melon, ${ }^{47}$ which is a $1 \mathrm{D}$ carbon amide imide nitride polymer with an ideal composition $\mathrm{C}_{6} \mathrm{~N}_{9} \mathrm{H}_{3} .{ }^{9}$ The nanocrystalline material was recently investigated by $\mathrm{X}$-ray and electron diffraction, solid-state NMR spectroscopy, and theoretical calculations. ${ }^{9}$

Melon consists of a layer structure well-ordered in two dimensions, but with a pronounced stacking disorder in the third. The structure of the layers was solved by projection from electron diffraction data (plane group $p 2 g g$ with $a=16.7 \AA$, $b=12.4 \AA, \gamma=90^{\circ}$ and $\left.Z=4\right)^{9}$ and is shown in Fig. 1. It is composed of infinite $1 \mathrm{D}$ chains of $\mathrm{NH}$-bridged heptazine $\left(\mathrm{C}_{6} \mathrm{~N}_{7}\left(\mathrm{NH}_{2}\right)_{3}\right)$ ) monomers with one terminal $\mathrm{NH}_{2}$ group. The chains exhibit a zigzag-type geometry and form a hydrogen bonded, 2D planar array. In agreement with other carbon nitrides (see above), the interlayer distance amounts to $3.2 \AA$.

The arrangement between neighboring layers exhibits a high degree of lateral disorder, which may be attributed to the much weaker dispersion forces dominating the interlayer arrangement. However, it is not completely stochastic as the X-ray powder diffraction data reveal asymmetric reflections besides the $00 l$ series. ${ }^{9}$ That certain layer arrangements are more favored than others is also indicated by the modulated intensity of the "streaking" observed in the SAED (selective area electron diffraction) patterns viewed perpendicular to $\mathrm{c}^{*}$ (see Fig. 1 (bottom)). The missing cone-like smearing in the $h k 0$ plane implies disorder originating from translational planar defects rather than rotational ones. ${ }^{9}$ Therefore, energetically similar stacking modes with various, yet not
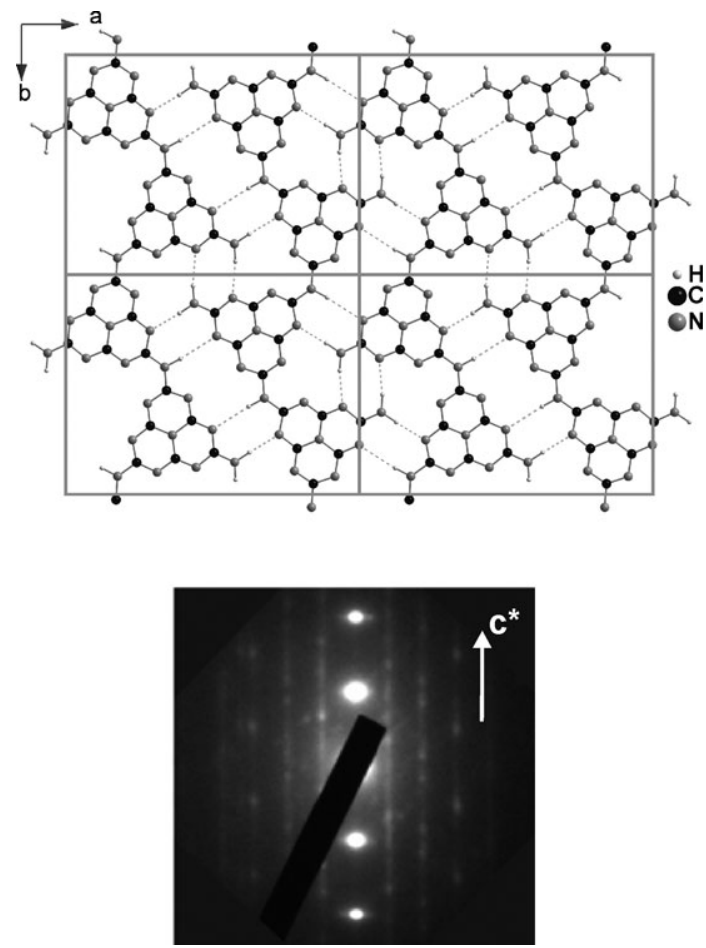

Fig. 1 (Top) Structure model for individual layers of melon. ${ }^{9}$ (bottom) SAED pattern perpendicular to the $c$ axis of the reciprocal lattice.

statistically distributed translational layer offsets are likely to contribute to the overall 3D structure.

\section{Experimental}

\subsection{Sample}

For a detailed description of the sample preparation for the work presented here refer to ref. 9. The sample was enriched in ${ }^{15} \mathrm{~N}$ to about $25 \%$.

\subsection{Solid-state NMR spectroscopy}

Solid-state NMR experiments were recorded on a commercial Avance II spectrometer (Bruker) operating at a proton frequency of $300 \mathrm{MHz}$. Samples were contained in $4 \mathrm{~mm}$ $\mathrm{ZrO}_{2}$ rotors for the ${ }^{15} \mathrm{~N}$ and ${ }^{13} \mathrm{C}$ measurements and in $2.5 \mathrm{~mm} \mathrm{ZrO}_{2}$ rotors for the ${ }^{1} \mathrm{H}$ experiments. Both were mounted in standard triple resonance MAS probes (Bruker). ${ }^{13} \mathrm{C}$ and ${ }^{1} \mathrm{H}$ shifts are reported with respect to TMS, ${ }^{15} \mathrm{~N}$ shifts were referenced to nitromethane. Data collection of the ${ }^{15} \mathrm{~N}$ and ${ }^{13} \mathrm{C}$ experiments was performed under broadband proton decoupling using a SPINAL-64 sequence with a nutation frequency of about $70 \mathrm{kHz}{ }^{48}$ The repetition times were set between 5 and $10 \mathrm{~s}$. In the $2 \mathrm{D}$ experiments quadrature detection of the $F_{1}$ domain was achieved via TPPI and a SPINAL-64 decoupling (nutation frequency about $70 \mathrm{kHz}$ ) was applied during $t_{1}$.

The 2D fpRFDR experiment was implemented as described in ref. 49 (see Fig. 2(a)). A spinning frequency of $12.5 \mathrm{kHz}$ was used which corresponds to a $180^{\circ}$ pulse length of $24 \mu$ s for the fpRFDR mixing pulses. The overall fpRFDR mixing time 
(a)

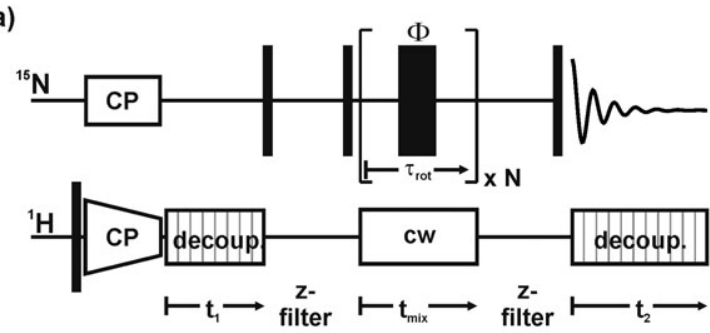

(b)
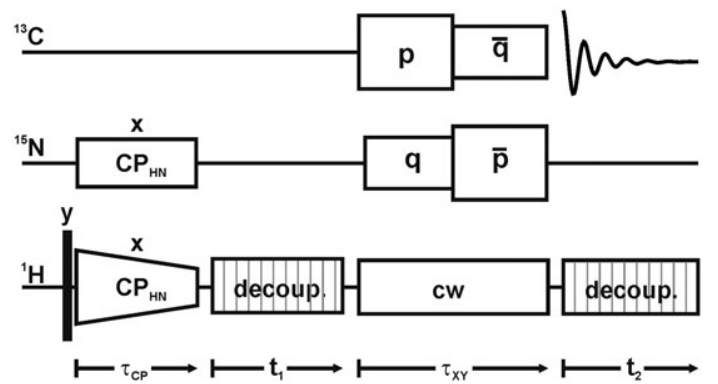

Fig. 2 Schematic representation of the pulse sequences (a) fpRFDR and (b) $i$ DCP. $c w$ denotes constant-wave decoupling times and decoup. composite pulse decoupling times (for further details refer to the text).

$\left(\tau_{\text {mix }}\right)$ was set to $115 \mathrm{~ms}$ and an XY-16 phase cycle $(\Phi)$ was applied for the $180^{\circ}$ pulses. $^{50}$ As preparation a ramped CP block was employed with a contact time of $3 \mathrm{~ms}$. Two additional delays of $30 \mathrm{~ms}$, before and after the fpRFDR mixing block, act as $z$-filters. $t_{1}$ was incremented rotorsynchronized $(80 \mu \mathrm{s})$ collecting 128 FIDs with 128 transients each. During the fpRFDR mixing time a cw decoupling with a nutation frequency of $85 \mathrm{kHz}$ was applied on the proton channel.

The $2 \mathrm{D}-i \mathrm{DCP}$ experiment was performed as presented in ref. 51 (see Fig. 2(b)). The spinning frequency was set to $5 \mathrm{kHz}$, the ${ }^{1} \mathrm{H}-{ }^{15} \mathrm{~N}$ CP contact time to $6 \mathrm{~ms}$ and the overall ${ }^{15} \mathrm{~N}-{ }^{13} \mathrm{C}$ contact time to $10 \mathrm{~ms}$. As shown in Fig. 2(b) the $i$ DCP pulse sequence of the ${ }^{15} \mathrm{~N}-{ }^{13} \mathrm{C}$ contact block $\tau_{X Y}$ is divided into two parts: during the first half the nutation frequency of ${ }^{15} \mathrm{~N}$ accounts to $\nu^{1}\left({ }^{15} \mathrm{~N}\right)=q \cdot \nu_{\text {Rot }}$ and of ${ }^{13} \mathrm{C}$ to $\nu^{1}\left({ }^{13} \mathrm{C}\right)=p \cdot \nu_{\text {Rot }}$ where $|p-q|=1$. Then nutation frequencies are switched to $\nu^{1}\left({ }^{15} \mathrm{~N}\right)=p \cdot \nu_{\text {Rot }}$ and $\nu^{1}\left({ }^{13} \mathrm{C}\right)=q \cdot \nu_{\text {Rot }}$. Simultaneously the phase of both channels is switched by $180^{\circ}$ (indicated by the bar in Fig. 2(b)). For our experiment $p$ and $q$ were set to 7 and 8 , respectively. A cw decoupling with a nutation frequency of $100 \mathrm{kHz}$ was used during the complete ${ }^{15} \mathrm{~N}-{ }^{13} \mathrm{C}$ contact time. Overall 124 experiments with 512 transients each were performed with a $t_{1}$ increment of $100 \mu \mathrm{s}$.

For the determination of the hydrogen substructure of melon we employed the strategy described previously in ref. 46. Details for the implementation of the LG-CP, the R14 pulse and the $\mathrm{CP}$ sequences can be found therein. For the LG-CP experiments ${ }^{52,53}$ a spinning frequency of $12 \mathrm{kHz}$ was used. The nutation frequency of the proton channel during the spin-lock was set to $60 \mathrm{kHz}$, to which the LG offset as well as the ${ }^{13} \mathrm{C}$ nutation frequency were optimized. The ${ }^{15} \mathrm{~N}$ excitation frequency was set to the middle of the $\mathrm{NH}$ and $\mathrm{NH}_{2}$ signals. A build-up curve of $361 \mathrm{D}$ experiments with 96 transients each was recorded. The LG-CP time $\tau_{\mathrm{CP}}$ was thereby increased in steps of $20 \mu$ s up to a maximum of $700 \mu$ s.

The symmetry-based ${ }^{1} \mathrm{H}-\mathrm{R} 14_{2}^{6}$ double-quantum experiments ${ }^{54,55}$ were set-up with an excitation-reconversion$\pi / 2$-acquisition scheme. For symmetric build-up curves the excitation and the reconversion time were incremented simultaneously $\left(\tau_{\mathrm{exc}}=\tau_{\text {rec }}\right)$ while for the constant-time (CT) procedure the reconversion time was decreased starting from $\tau_{\text {total }}$ with equal timesteps as the excitation time was increased $\left(\tau_{\text {exc }}+\tau_{\text {rec }}=\tau_{\text {total }}\right)$. For the experiments at a spinning frequency of $30 \mathrm{kHz}$ a simple $180_{\Phi}^{\circ}$ pulse was used for the $\mathrm{R}$ block of the $\mathrm{R} 14_{2}^{6}$ sequence. In contrast, at a spinning frequency of $15 \mathrm{kHz}$ the composite pulse $90_{\Phi}^{\circ}-270_{-\Phi}^{\circ}$ was applied for a better chemical shift compensation. The phase $\Phi$ was optimized to $77.04^{\circ}$ for $\nu_{\text {rot }}=30 \mathrm{kHz}$ and to $76.29^{\circ}$ for $\nu_{\text {rot }}=15 \mathrm{kHz}$. A total of $321 \mathrm{D}$ experiments were measured for the symmetric build-up curves while for the CT curves 17 and $91 \mathrm{D}$ experiments were performed for $\nu_{\text {rot }}=30$ and $15 \mathrm{kHz}$, respectively. The increment of the excitation time in subsequent $1 \mathrm{D}$ experiments accounted for one $\mathrm{RR}^{\prime}$ element which corresponds to $9.52 \mu \mathrm{s}$ at $\nu_{\mathrm{rot}}=30 \mathrm{kHz}$ and to $19.05 \mu \mathrm{s}$ at $\nu_{\text {rot }}=15 \mathrm{kHz}$. 16 repetitions for each $1 \mathrm{D}$ experiment were performed.

For the cross polarization $(\mathrm{CP})$ experiments a standard $\mathrm{CP}$ experiment was used. ${ }^{56}$ The spinning frequency was set to $4 \mathrm{kHz}$ in order to prevent suppression of spin-diffusion. For the optimization of the Hartmann-Hahn match attention was paid to ensure a Hartmann-Hahn condition of $n= \pm 1$. Therefore nutation frequencies were preoptimized using $90^{\circ}$ pulses and then fine-tuned in the CP experiment. 22 1D $\mathrm{CP}$-experiments were measured incrementing the $\mathrm{CP}$ contact time from 0.1 to $20 \mathrm{~ms} .1024$ transients were recorded for each FID. In advance of the measurement of the $\mathrm{CP}$ build-up curves we checked the dephasing behavior of the magnetization of ${ }^{1} \mathrm{H}$ and ${ }^{13} \mathrm{C}$ during the spin-locks using the pulse sequences presented in ref. 56. These revealed no significant dephasing in the relevant timescale of $20 \mathrm{~ms}\left(\mathrm{~T}_{1 \rho}\right.$ was estimated to some hundred milliseconds for both ${ }^{1} \mathrm{H}$ and ${ }^{13} \mathrm{C}$ ). $\mathrm{T}_{1 \rho}$ could thus be neglected in the analysis of the $\mathrm{CP}$ data.

\subsection{Solid-state NMR simulations}

Simulations for the LG-CP and the R14 experiments were performed with the simulation package SIMPSON ${ }^{57}$ For the fits of the simulated curves to experimental data least-square fits were performed using the fit routine lsqcurvefit of MATLAB $^{58}$ in a self-developed script which internally calls the program SIMPSON.

For the simulations of the LG-CP pulse sequence spinsystems consisting of one $\mathrm{NH}$ and $\mathrm{NH}_{2}$ group were built. CSA parameters were found to have only minor influence on the build-up curves and were therefore omitted. For the same reason the $\mathrm{H}-\mathrm{N}-\mathrm{H}$ angle of the $\mathrm{NH}_{2}$ group could be set fixed to the value derived from force field calculations. However, for a correct simulation of the LG-CP conditions the proton isotropic chemical shift was set to the required LG offset of $-42426 \mathrm{~Hz}$ corresponding to the spinning frequency of $12 \mathrm{kHz}$ and to the ${ }^{1} \mathrm{H}$ nutation frequency of $60 \mathrm{kHz}$. As the build-up curves for the two $\mathrm{NH}$ signals as well as for the two 
$\mathrm{NH}_{2}$ signals run identically their intensities were summed up in each case. For both intensities $\left(\mathrm{NH}\right.$ and $\mathrm{NH}_{2}$ ) the optimal $\mathrm{N}-\mathrm{H}$ distance was then determined with MATLAB as described above under variation of the $\mathrm{N}-\mathrm{H}$ distance and an overall scaling factor.

The procedure of the extraction of the $\mathrm{H}-\mathrm{H}$ distances from the $\mathrm{R} 14_{2}^{6}$ data was described in detail in ref. 46. A spin-system consisting of two protons and their common dipole coupling was used.

For the calculation of the 2 nd moments $\left(M_{2}\right)$ (see Results) a MATLAB script was developed. For each structure model both the heteronuclear $M_{2}^{\mathrm{HC}}$ and the homonuclear $M_{2}^{\mathrm{HH}}$ were calculated including atoms within a sphere with a radius of $30 \AA$ around each crystallographically independent atom. For the $M_{2}^{\mathrm{HH}}$ the individual homonuclear moments for all hydrogen atoms of the unit cell were summed up as all hydrogen atoms participate in the polarization transfer during the $\mathrm{CP}$ spinlock. The individual $M_{2}^{\mathrm{HC}}$ of the $\mathrm{CN}_{3}$ and of the $\mathrm{CN}_{2}\left(\mathrm{NH}_{x}\right)$ atoms were added separately to give the heteronuclear $M_{2}^{\mathrm{HC}}\left(\mathrm{CN}_{3}\right)$ and $M_{2}^{\mathrm{HC}}\left(\mathrm{CN}_{2}\left(\mathrm{NH}_{x}\right)\right)$, respectively.

\subsection{Computational methods}

The force field calculations were carried out with the program package MS modeling 4.0 ${ }^{59}$ using the Dreiding force field. As a starting point for the layer displacements the force field optimized unit cell from ref. 9 was taken as well as the Hirschfeld charges determined from a cluster calculation on the DFT level. For the calculation of the energy, structure models with lateral displacements were generated by shifting these layers in steps of $4 \%$ of the cell constants with a fixed layer distance of $3.19 \AA$. The energies were then calculated without further optimization.

For the geometry optimization of the minima of the force field hypersurface the unit cells with shift vectors $\vec{S}=[16 \% 12 \%]$, $\vec{S}=\left[\begin{array}{ll}0 \% & 24 \%\end{array}\right]$ and $\vec{S}=\left[\begin{array}{ll}36 \% & 36 \%\end{array}\right]$ were fully relaxed (optimization of all fractional coordinates and all cell constants) in space group $P 1$ with the Quasi-Newton algorithm, the Dreiding force field and Hirschfeld charges.

\section{Results}

\subsection{Phase homogeneity}

Fig. 3(a) shows a ${ }^{15} \mathrm{~N}$ CP-MAS spectrum of melon. Due to a strong and very well optimized proton decoupling we can resolve two signals each for both the $\mathrm{NH}$ and the $\mathrm{NH}_{2}$ groups. The 2D structure solution for the layers from the electron diffraction data however exhibits only one crystallographically independent nitrogen atom for both the $\mathrm{NH}$ and the $\mathrm{NH}_{2}$ groups. Either these separated signals originate from different phases or the 2D symmetry and thus the equality of the $\mathrm{N}$ atoms of the electron diffraction data is not conserved in three dimensions. The latter may be caused by a non-eclipsed arrangement of the layers.

Therefore we examined the phase homogeneity of our sample with a ${ }^{15} \mathrm{~N}$-fpRFDR spin-diffusion experiment (see Fig. 3(b)). With a mixing time of $115 \mathrm{~ms}$ the signals have common cross signals if the involved nuclei are positioned within a range of several nanometres and thus are in the same
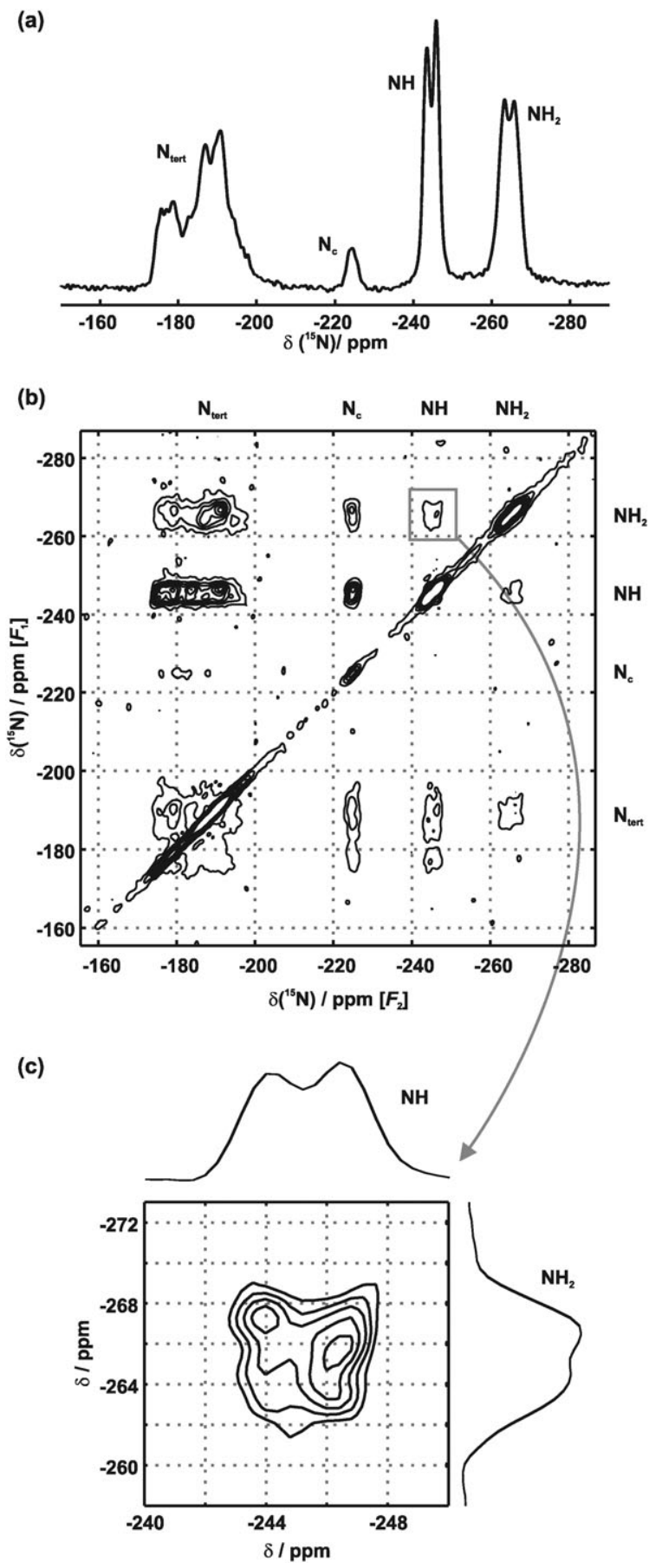

Fig. 3 (a) ${ }^{15} \mathrm{~N}$ CP-MAS spectrum of melon; ${ }^{15} \mathrm{~N}-f p R F D R$ spindiffusion spectrum with a mixing time of $115 \mathrm{~ms}$ : complete spectrum (b) and extension of the $\mathrm{NH}_{2} \rightarrow \mathrm{NH}$ correlation peak (c).

phase. As preparation block for this spectrum a short CP mixing time of $3 \mathrm{~ms}$ was used which guarantees a high excitation of the $\mathrm{NH}$ and the $\mathrm{NH}_{2}$ signals. For an effective excitation of the central nitrogen atom $\left(\mathrm{N}_{c}\right)$ a longer $\mathrm{CP}$ mixing time would have been necessary which is why in the $F_{1}$ dimension the corresponding signal is very weak $\left(\delta\left(\mathrm{N}_{c}\right) \approx 225 \mathrm{ppm}\right)$. Nevertheless, the spectrum shows cross signals for all other signals in the $F_{1}$ dimension with the $\mathrm{N}_{c}$ signal in the $F_{2}$ dimension. This reflects an intensity transfer 
from all other nuclei to the $\mathrm{N}_{c}$ nucleus and thus proves that all phases of the sample must exhibit a heptazine subunit for which the $\mathrm{N}_{c}$ atom is unique.

The enlarged depiction of the correlation signals of the $\mathrm{NH}$ and $\mathrm{NH}_{2}$ groups in Fig. 3(c) reveals that both $\mathrm{NH}$ signals correlate with both $\mathrm{NH}_{2}$ signals and vice versa. Additionally, all tertiary nitrogen signals $\left(\mathrm{N}_{\text {tert }}\right)$ show doublets as correlation signals with the $\mathrm{NH}_{x}$ signals. Thus, the $\mathrm{NH}, \mathrm{NH}_{2}$ and $\mathrm{N}_{\text {tert }}$ groups must be positioned in the same phase. The split $\mathrm{NH}$ and $\mathrm{NH}_{2}$ signals thus have to represent crystallographically inequivalent $\mathrm{NH}$ and $\mathrm{NH}_{2}$ groups within one phase.

\section{2 $\quad{ }^{13} \mathrm{C}$-Signal assignment}

In the following section we will employ a strategy suited to derive information about the three-dimensional structure of melon based on ${ }^{1} \mathrm{H}-{ }^{13} \mathrm{C}$ CP rates ${ }^{46}$ The prerequisite for this analysis, however, is an exact knowledge of the hydrogen substructure which will be determined in the next sections. Additionally, it considerably improves the expressiveness of the rate experiments if all ${ }^{13} \mathrm{C}$ signals are assigned so that no sum intensities of signals have to be used. The ${ }^{13} \mathrm{C}$ CP-MAS spectrum of melon in Fig. 4(a) reveals two signal groups at 157 and $164 \mathrm{ppm}$ which were previously assigned to the $\mathrm{CN}_{3}$ and the $\mathrm{CN}_{2}\left(\mathrm{NH}_{x}\right)$ carbon atoms, respectively. ${ }^{9}$ However the origin for the shoulder in the signal at $164 \mathrm{ppm}$ could not yet be determined. In order to differentiate between the $\mathrm{CN}_{2}(\mathrm{NH})$ and the $\mathrm{CN}_{2}\left(\mathrm{NH}_{2}\right)$ carbon signals we performed a $2 \mathrm{D}^{15} \mathrm{~N}-{ }^{13} \mathrm{C}$ correlation experiment. Fig. 4 shows the 2D-iDCP experiment of melon with ${ }^{15} \mathrm{~N}-{ }^{13} \mathrm{C}$ mixing time of $10 \mathrm{~ms}$ which guarantees an excitation of bonded $\mathrm{N}-\mathrm{C}$ connectivities only.

As expected the spectrum shows correlations with both ${ }^{13} \mathrm{C}$ signals for the outer tertiary nitrogen atoms $\left(\mathrm{N}_{\text {tert }}\right)$, as each $\mathrm{N}_{\text {tert }}$ atom is bonded to a $\mathrm{CN}_{3}$ and a $\mathrm{CN}_{2}\left(\mathrm{NH}_{x}\right)$ carbon atom. The central nitrogen atom $\left(\mathrm{N}_{c}\right)$ at $\delta\left({ }^{15} \mathrm{~N}\right)=-225 \mathrm{ppm}$ correlates only with the $\mathrm{CN}_{3}$ carbon atom in agreement with the chemical structure. This signal is very weak due to the poor $\mathrm{CP}$ excitation of the $\mathrm{N}_{c}$ signal (see fpRFDR experiment). Additionally, for the $\mathrm{CN}_{2}\left(\mathrm{NH}_{x}\right)$ signal correlations with the $\mathrm{NH}$ and $\mathrm{NH}_{2}$ signals are obtained. As emphasized by the gray arrows in Fig. 4 the $\mathrm{NH}_{2}$ signal correlates with the main resonance of the $\mathrm{CN}_{2}\left(\mathrm{NH}_{x}\right)$ signal (166 ppm) while the $\mathrm{NH}$ signal reveals a common signal with both the main signal (166 ppm) and the shoulder (163 ppm).

This distribution of ${ }^{13} \mathrm{C}$ chemical shifts however impedes an extraction of individual intensities for the $\mathrm{CN}_{2}(\mathrm{NH})$ and the $\mathrm{CN}_{2}\left(\mathrm{NH}_{2}\right){ }^{13} \mathrm{C}$ signals, as in the main signal both overlap heavily. In the analysis of the ${ }^{1} \mathrm{H}-{ }^{13} \mathrm{C}$ cross-polarization experiment we therefore have to restrict it to the analysis of two build-up curves, namely for the $\mathrm{CN}_{3}$ and the $\mathrm{CN}_{2}\left(\mathrm{NH}_{x}\right)^{13} \mathrm{C}$ signals.

\subsection{Localization of hydrogen atoms}

We recently proved that the exact knowledge of the hydrogen substructure is a prerequisite for a reasonable quantitative analysis of $\mathrm{CP}$ rates. ${ }^{46} \mathrm{We}$ demonstrated that even the accuracy of theoretical calculations with DFT methods is not sufficient. Therefore we established a strategy for an accurate localization of the hydrogen atoms which includes the measurement of (a)

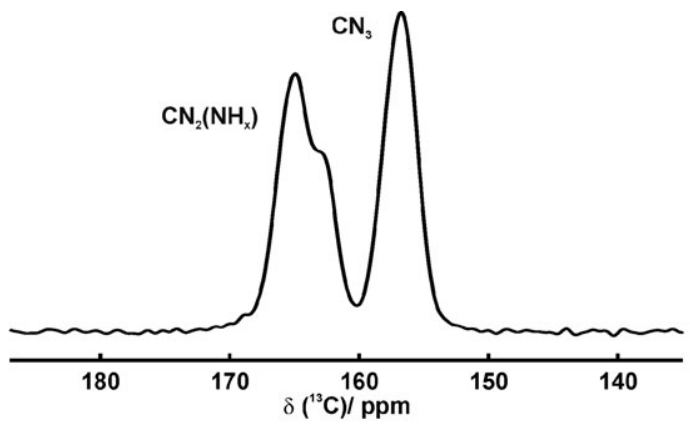

(b)

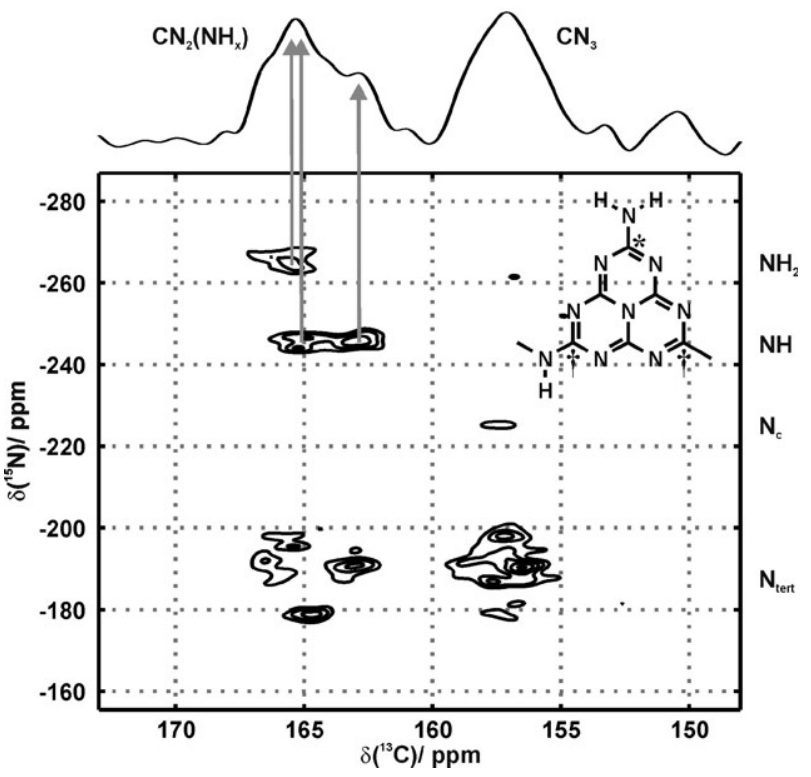

Fig. 4 (a) ${ }^{13} \mathrm{CP}-\mathrm{MAS}$ spectrum of melon; (b) $2 \mathrm{D}{ }^{15} \mathrm{~N}-{ }^{13} \mathrm{C} i \mathrm{DCP}$ spectrum ${ }^{51}$ of melon with a ${ }^{15} \mathrm{~N}-{ }^{13} \mathrm{C}$ contact time of $10 \mathrm{~ms}$. The correlation peaks indicate through-bond ${ }^{15} \mathrm{~N}-{ }^{13} \mathrm{C}$ proximities. The gray arrows mark the correlations of the $\mathrm{NH}$ and $\mathrm{NH}_{2}$ signals with the $\mathrm{CN}_{2}\left(\mathrm{NH}_{x}\right)$ signals. The insert shows the subunit of the structure of melon where * denotes $\mathrm{CN}_{2}\left(\mathrm{NH}_{2}\right)$ and $\dagger \mathrm{CN}_{2}(\mathrm{NH})$ groups.

$\mathrm{N}-\mathrm{H}$ and $\mathrm{H}-\mathrm{H}$ distances via NMR. For melon we used a Lee-Goldburg cross-polarization (LG-CP) experiment for measuring the $\mathrm{NH}$ distances in the $\mathrm{NH}$ and the $\mathrm{NH}_{2}$ group and a $\mathrm{R} 14_{2}^{6}$ pulse sequence for determining the $\mathrm{H}-\mathrm{H}$ distance in the $\mathrm{NH}_{2}$ group. The experiments were performed as outlined in ref. 46. These data were subsequently incorporated into the force field structure under retention of the torsion angles for the $\mathrm{NH}_{x}$ groups.

3.3.1 Determination of $\mathbf{N}-\mathbf{H}$ distances. Fig. 5 shows the ${ }^{15} \mathrm{~N}$ LG-CP build-up curves for the $\mathrm{NH}$ and the $\mathrm{NH}_{2}$ groups of melon. As demonstrated in ref. 46 the evaluation of these curves can be performed without taking into account further remote protons of the structure if only the first oscillation is utilized. This results in an $\mathrm{N}-\mathrm{H}$ distance of 1.024(1) $\AA$ for the $\mathrm{NH}$ group and of 1.043(3) $\AA$ for the $\mathrm{NH}_{2}$ group.

3.3.2 Determination of $\mathbf{H}-\mathbf{H}$ distances. The determination of the $\mathrm{H}-\mathrm{H}$ distance allows for a calculation of the $\mathrm{H}-\mathrm{N}-\mathrm{H}$ angle of the $\mathrm{NH}_{2}$ group when combined with the $\mathrm{N}-\mathrm{H}$ 

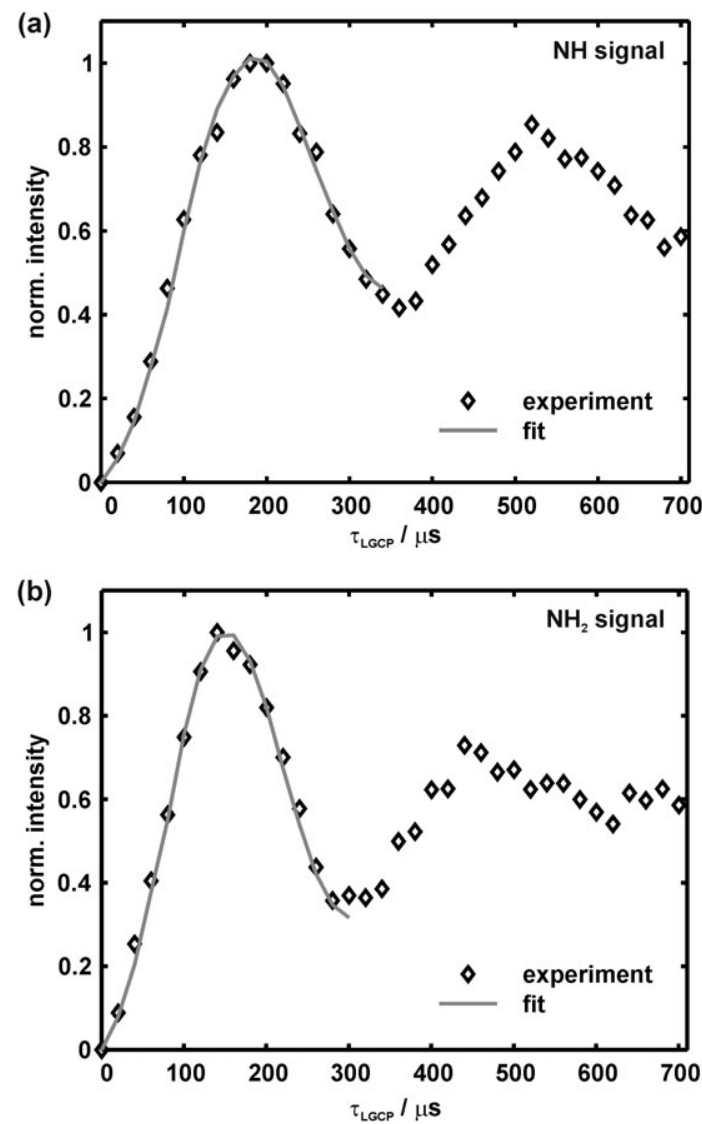

Fig. 5 Experimental ${ }^{15} \mathrm{~N}-\mathrm{LG}-\mathrm{CP}$ build-up curves $(\diamond)$ of the NH (a) and the $\mathrm{NH}_{2}$ (b) signal of melon with fit (line) using a 2- and a 3 -spin system for the $\mathrm{NH}$ and $\mathrm{NH}_{2}$ curve, respectively.

distance. It was derived with the symmetry-based doublequantum sequence $\mathrm{R} 14_{2}^{6}$. Both symmetric and constant-time build-up curves were measured at spinning frequencies $\left(\nu_{\text {rot }}\right)$ of 15 and $30 \mathrm{kHz}$. Especially the averaged value of these four experiments yields a very accurate $\mathrm{H}-\mathrm{H}$ distance. Fig. 6(a) shows the ${ }^{1} \mathrm{H}$ spectrum of melon with its deconvoluted resonances. The ${ }^{1} \mathrm{H}$ signal of the $\mathrm{NH}$ group can be found at $9.5 \mathrm{ppm}$ while the signal of the $\mathrm{NH}_{2}$ arises at $10 \mathrm{ppm}$. The two further minor signals are to be assigned to impurities from the probe. This assignment is corroborated since in the doublequantum excitation curve only the short $\mathrm{H}-\mathrm{H}$ distance of the $\mathrm{NH}_{2}$ group results in fast oscillations while the $\mathrm{NH}$ signal shows a slow build-up without oscillations. This is presented exemplarily in Fig. 6(b) for the symmetric build-up curve at $\nu_{\text {rot }}=30 \mathrm{kHz}$.

Our previous studies on melem revealed that the influence of weaker $\mathrm{H}-\mathrm{H}$ couplings from remote hydrogen atoms have to be considered for long excitation times only. ${ }^{46}$ Restricting the analysis however to the first oscillations simulations with 2-spin systems can be employed for a reasonable analysis of build-up curves. We could show for melem $\left(\mathrm{C}_{6} \mathrm{~N}_{7}\left(\mathrm{NH}_{2}\right)_{3}\right)$ that this is fulfilled with an excitation time of $80 \mu \mathrm{s}$ in symmetric and for an overall time $\tau_{\text {total }}=\tau_{\text {exc }}+\tau_{\text {rec }}$ of $160 \mu \mathrm{s}$ in constant-time build-up curves. Since in melon the hydrogen atoms are more diluted than in melem these values are appropriate for melon as well.
Table $1{ }^{1} \mathrm{H}-{ }^{1} \mathrm{H}$ distance of the $\mathrm{NH}_{2}$ group of melon from the $\mathrm{R} 14_{2}^{6}$ experiments

\begin{tabular}{lll}
\hline$\nu_{\text {rot }}$ & $30 \mathrm{kHz}$ & $15 \mathrm{kHz}$ \\
\hline Symmetric & $1.77(2) \AA \AA$ & $1.82(2) \AA$ \\
Constant-time & $1.75(1) \AA$ & $1.80(1) \AA$ \\
\hline
\end{tabular}

In Fig. 6(b)-(e) the experimental symmetric and constanttime build-up curves of the $\mathrm{NH}_{2}$ signal of melon, each with $\nu_{\text {rot }}=15$ and $30 \mathrm{kHz}$, are shown. Additionally, the Figure depicts the 2-spin simulations matching best the experimental data. The thus obtained distances are given in Table 1, their average value amounts to $1.785 \AA$. In combination with an $\mathrm{N}-\mathrm{H}$ distance of $1.04 \AA$ this corresponds to an $\mathrm{H}-\mathrm{N}-\mathrm{H}$ angle of $118.2^{\circ}$ for the $\mathrm{NH}_{2}$ group.

\section{4 ${ }^{1} \mathrm{H}-{ }^{13} \mathrm{C}$ cross-polarization experiments}

The successful determination of the hydrogen substructure of melon allowed for the extraction of structure information with cross-polarization (CP) build-up curves which will be described in the following. ${ }^{46}$ The initial slope for each signal can be extracted via the logarithmic plot of a normalized $\mathrm{CP}$ build-up curve. It represents the experimental mean $\mathrm{CP}$ rate constant $\langle k\rangle$. On the other hand $\langle k\rangle$ can be calculated from the rates $k_{\mathrm{CP}}$ of all crystallographic independent nuclei (j) overlapping to the corresponding signal in the ${ }^{13} \mathrm{C}$ MAS spectrum:

$$
\langle k\rangle=\frac{1}{N} \sum_{j}^{N} k_{\mathrm{CP}}(j)
$$

The rates $k_{\mathrm{CP}}$ reflect the transfer of polarization from ${ }^{1} \mathrm{H}$ to ${ }^{13} \mathrm{C}$ (or any other $I=1 / 2$-nucleus) and are connected with the homo- and heteronuclear second moments $M_{2}^{\mathrm{HH}}$ and $M_{2}^{\mathrm{HC}}$ via

$$
k_{\mathrm{CP}}=C_{\mathrm{CP}} \frac{M_{2}^{\mathrm{HC}}}{\sqrt{M_{2}^{\mathrm{HH}}}}
$$

where the constant $C_{\mathrm{CP}}$ depends solely on physical constants and the experimental setup but contains no structural information. The second moment $M_{2}^{X Y}$ can be calculated from a structure model by

$$
M_{2}^{X Y}=\left(\frac{1}{2 \pi}\right)^{2} \frac{4}{5}\left(\frac{1}{2} \gamma_{I} \gamma_{S} \hbar \frac{\mu_{0}}{4 \pi}\right)^{2} \sum_{i}\left(r_{i}^{X Y}\right)^{-6}
$$

Thus, for the verification of a structure model $\langle k\rangle$ can be determined for each observed signal while the second moments are computed from the model. The structure model used is then confirmed if the constant $C_{\mathrm{CP}}$ is found to be equal for all signals. ${ }^{46,60}$ In the following we will employ this condition for the determination of the lateral arrangement of the layers in melon.

In melon we can differentiate the two resolved ${ }^{13} \mathrm{C}$ signals $\mathrm{CN}_{2}\left(\mathrm{NH}_{x}\right)$ and $\mathrm{CN}_{3}$ as shown above. So it is possible to evaluate structure models with different lateral arrangements by the equality of $C_{\mathrm{CP}}\left(\mathrm{CN}_{2}\left(\mathrm{NH}_{x}\right)\right)$ and $C_{\mathrm{CP}}\left(\mathrm{CN}_{3}\right)$ or, as it will be done in the following, by their ratio $C_{\mathrm{CP}}\left(\mathrm{CN}_{3}\right)$ / $C_{\mathrm{CP}}\left(\mathrm{CN}_{2}\left(\mathrm{NH}_{x}\right)\right)$ which must equal 1 for the most likely models. 

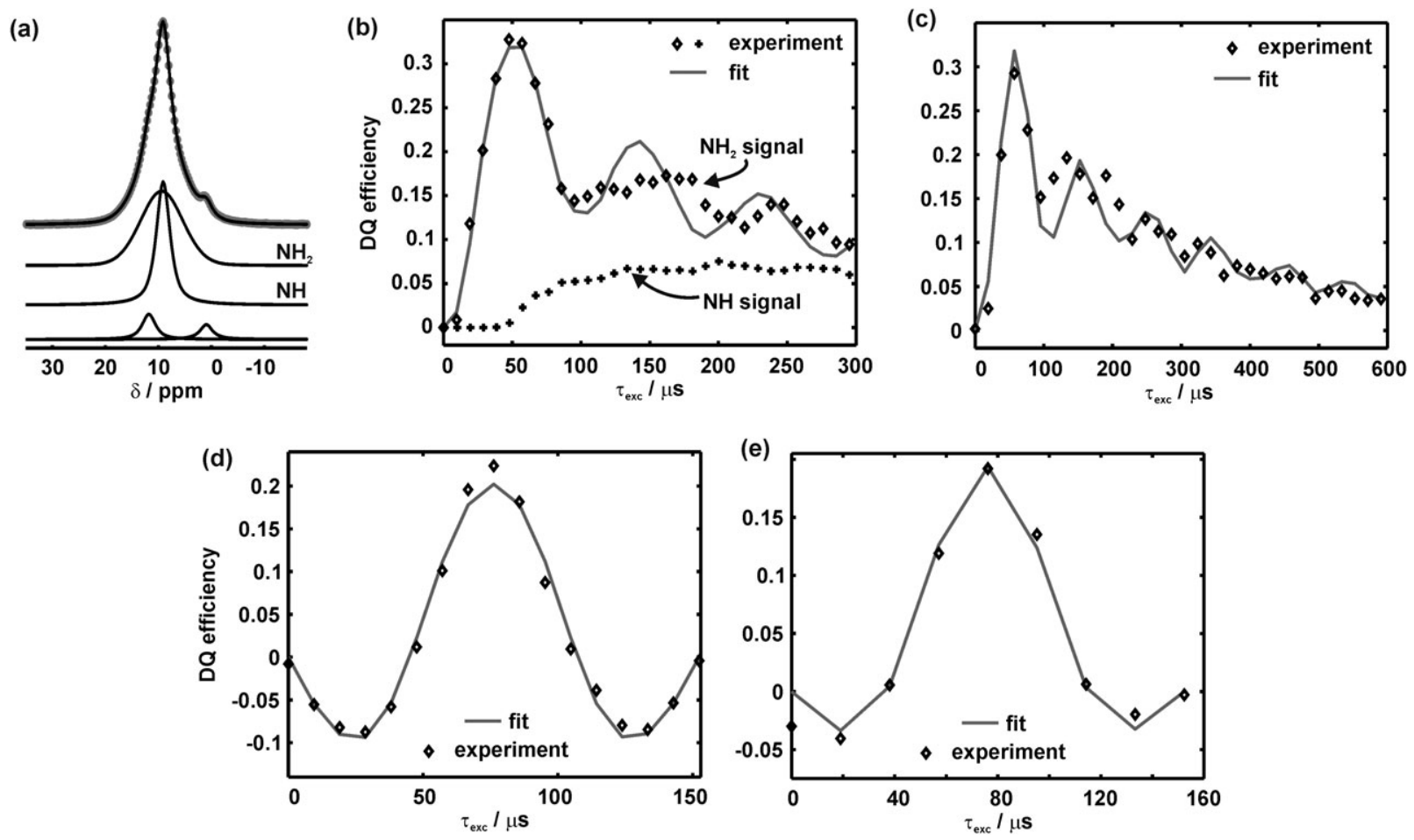

Fig. 6 (a) ${ }^{1} \mathrm{H}$ spectrum of melon ( $)$ with fit (top) and deconvoluted signals (bottom); (b)-(e) Experimental $\mathrm{R} 14_{2}^{6}$ build-up curves $(\diamond)$ of the $\mathrm{NH}_{2}$ signal with a fit of a 2-spin systems (line): (b) symmetric curve at $\nu_{\text {rot }}=30 \mathrm{kHz}$; (c) symmetric curve at $\nu_{\text {rot }}=15 \mathrm{kHz}$; (d) constant-time curve at $\nu_{\text {rot }}=30 \mathrm{kHz}$; (e) constant-time curve at $\nu_{\text {rot }}=15 \mathrm{kHz}$. In (b) the experimental build-up curve of the NH signal is additionally shown ( + ).

Fig. 7(a) shows the logarithmic plot of the normalized CP build-up curves for the ${ }^{13} \mathrm{C}$ signals of melon. From this data the initial slopes were determined (see lines in Fig. 7(a)) which result in the averaged rates $\langle k\rangle$ of $0.86 \times 10^{3} \mathrm{~Hz}$ for the $\mathrm{CN}_{3}$ and of $2.59 \times 10^{3} \mathrm{~Hz}$ for $\mathrm{CN}_{2}\left(\mathrm{NH}_{x}\right)$ signal.

For the calculation of the second moments the force field optimized structure from ref. 9 was utilized. The $\mathrm{N}-\mathrm{H}$ distances and the $\mathrm{H}-\mathrm{N}-\mathrm{H}$ angle for the $\mathrm{NH}$ and the $\mathrm{NH}_{2}$ groups were corrected according to the results of the NMR experiments presented above. Subsequently, structure models with varying lateral shifts in $a$ and $b$ were generated which in the following will be characterized by the shift vector $\mathbf{S}=[\Delta a \Delta b]$ where $\Delta a$ and $\Delta b$ are the lateral shifts along the $a$ and $b$ axis, respectively. Thus, the used models correspond to an AAA stacking of the layers of melon. For all these structures the corresponding second moments and, in combination with the experimental values for $\langle k\rangle$, the constants $C_{\mathrm{CP}}$ were computed for each of the two signals.

Fig. 7(b) depicts the dependency of their ratio $C_{\mathrm{CP}}\left(\mathrm{CN}_{3}\right) /$ $C_{\mathrm{CP}}\left(\mathrm{CN}_{2}\left(\mathrm{NH}_{x}\right)\right)$ on the shift vector $\mathbf{S}$. This hypersurface is symmetric in $\Delta a$ and $\Delta b$ due to the symmetry of the layers (see Fig. 1). Therefore, the following discussion will only refer to shift vectors between 0 and $50 \%$ for $\Delta a$ and $\Delta b$ covering the "asymmetric unit" of the hypersurface.

In the hypersurface the dark areas represent structure models with a ratio close to 1 which are the more suitable models. A wide range of ratios from 1.19(1) to 1.63(2) is covered. This shows that there are layer arrangements which reproduce the experimental data better than others and thus, that from the $\mathrm{CP}$ data preferred lateral shifts can be identified. The best results with a ratio of 1.19 can be found for the shift vectors $\mathbf{S}=[0 \% 50 \%], \mathbf{S}=[50 \% 50 \%]$ and $\mathbf{S}=$ $[25 \% 0 \%]$. However, none of the models used reaches a ratio of 1 . This can be explained by the fact that the structure of melon is disordered and we employ a well-ordered model which only approximately reflects the reality. The largest ratios arise for the shift vectors $\mathbf{S}=[0 \% 0 \%], \mathbf{S}=[50 \% 0 \%]$ and $\mathbf{S}=[25 \% 50 \%]$

In order to examine the influence of free relaxation of the structures on the ratio the structure models of the minima were optimized with force field methods. These optimizations resulted in minor changes of the geometry of the layers. Correspondingly, the ratio $C_{\mathrm{CP}}\left(\mathrm{CN}_{3}\right) / C_{\mathrm{CP}}\left(\mathrm{CN}_{2}\left(\mathrm{NH}_{x}\right)\right)$ of optimized cells differ only up to 0.02 from the previously used fixed layers which justifies their utilization for the hypersurface from Fig. 7(b).

Finally, we examined if more elaborate structure models result in a ratio closer to 1 . Instead of the used AAA model we employed an ABA model with two different shift vectors for $\mathrm{A} \rightarrow \mathrm{B}$ and $\mathrm{B} \rightarrow \mathrm{A}$. Thus, layers possess unequal lateral arrangements with their two neighboring layers. However, with these models the minimal ratio once more amounted to 1.19. The structures of these minima represent combinations of the structural motifs of the minima in the AAA model, e.g. a shift of $\mathbf{S}=[0 \% 50 \%]$ for $\mathrm{A} \rightarrow \mathrm{B}$ in combination with a shift of $\mathbf{S}=[25 \% 0 \%]$ for $\mathrm{B} \rightarrow \mathrm{A}$. This demonstrated that primarily the adjacent layers contribute to the second moments while there is only a minor influence from more distant layers. 
(a)

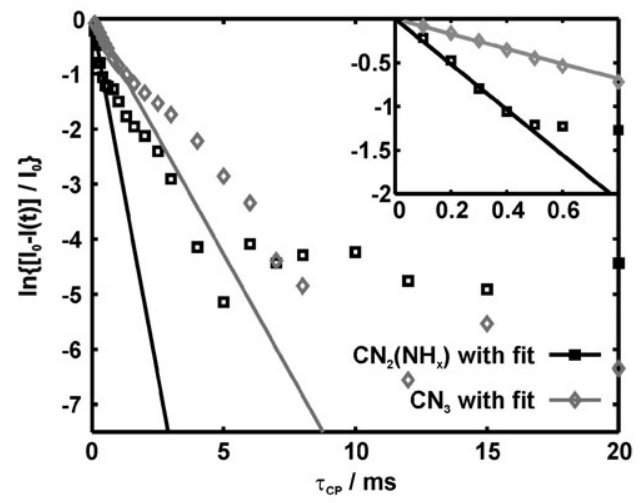

(b)

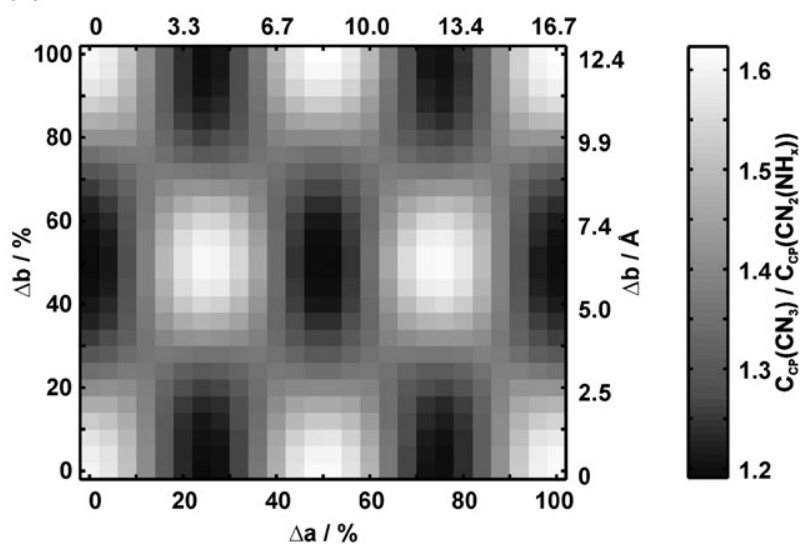

Fig. 7 (a) Logarithmic plot of the normalized ${ }^{13} \mathrm{C}-\mathrm{CP}$ build-up curves of melon (symbols) with linear fits of the initial gradient (solid line); (b) $\mathrm{CP}$ hypersurface: dependency of the ratio $C_{\mathrm{CP}}\left(\mathrm{CN}_{3}\right) / C_{\mathrm{CP}}\left(\mathrm{CN}_{2}\left(\mathrm{NH}_{x}\right)\right)$ on the lateral shift vector $\mathbf{S}=[\Delta a \Delta b]$.

\subsection{Force field energies}

The calculations of relative force field energies were used as complementary information for the determination of preferred lateral shifts in the layered structure of melon. Since the energy changes expected are caused by van der Waals interactions only, the variation on the energy hypersurface will be small and may even be smaller than the absolute error which arises in force field calculations. Even modern force fields usually do not reach an absolute accuracy better than 1-4 $\mathrm{kcal} \mathrm{mol}^{-1}{ }^{61,62}$ To ensure the significance of the following analysis we, therefore, validated the Dreiding force field for use with melon. Already in a previous study ${ }^{9}$ it was demonstrated that this force field reproduces the lattice parameters $(a=16.7-16.8 \AA \mathrm{\AA} / b=$ $12.8 \AA)$ as well as the interlayer distance $(c=3.19 \AA)$ within the experimental error. Especially the observed planarity of the individual layers caused by the tight $\mathrm{N}-\mathrm{H} \cdots \mathrm{N}$ hydrogen bond network is retained in excellent agreement. Shifting mainly rigid layers against each other, however, leaves the error in the absolute energies constant. By turning to relative energies this error is mainly cancelled which allows to discuss the energy hypersurface as well as structure models derived from the force field calculations based on laterally shifted layers.

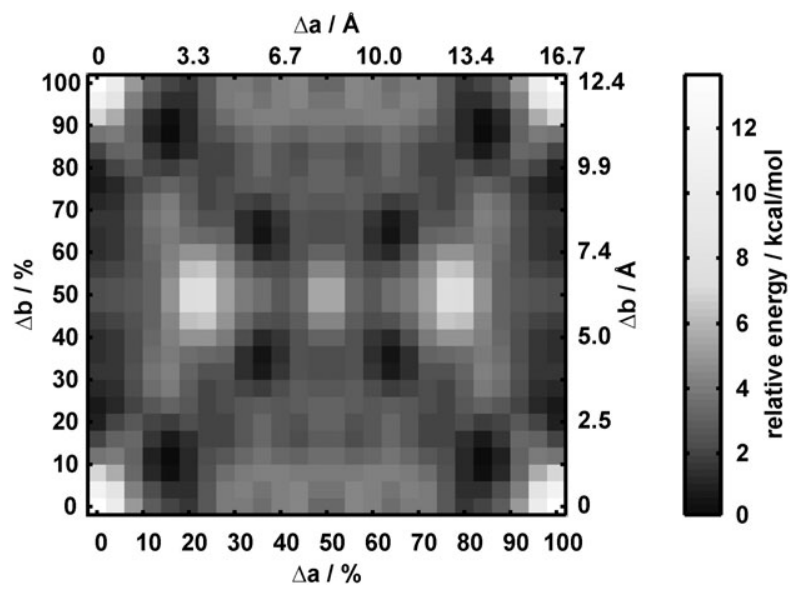

Fig. 8 Energy hypersurface: dependency of the relative force field energy on the lateral shift vector $\mathbf{S}=[\Delta a \Delta b]$.

We employed the same models as for the analysis of the CP rates but left the positions of the hydrogen atoms unchanged in order to guarantee consistency within the force field calculations. Fig. 8 shows the resulting energy hypersurface which is symmetric with respect to $\Delta a$ and $\Delta b$ as is the $\mathrm{CP}$ hypersurface. The color coding was chosen in a way to label those lateral shifts in black to dark gray which are up to $2 \mathrm{kcal} \mathrm{mol}^{-1}$ above the global minimum and are thus energetically accessible at ambient temperature.

As most regions of the hypersurface are colored black to dark grey we can conclude that the lateral displacement of adjacent layers leads to a very flat energy profile. This is in agreement with the experimental results where a distribution of lateral shifts and thus a disorder is found. However, some lateral shifts are definitely unfavored with energies up to $12 \mathrm{kcal} \mathrm{mol}^{-1}$ above the minimum. This explains why the disorder is not completely statistical but exhibits preferred arrangements.

The maximum on the hypersurface occurs at $\mathbf{S}=[0 \% 0 \%]$. This corresponds to the ecliptic position of the layers. Further local maxima are positioned at about $\mathbf{S}=[20 \% 50 \%]$ as well as at $\mathbf{S}=[50 \% 50 \%]$. Here the heptazine units in adjacent layers are arranged partially ecliptic.

The minima are situated at about $\mathbf{S}=\left[\begin{array}{ll}0 \% & 24 \%\end{array}\right], \mathbf{S}=$ [16\% $12 \%]$ and $\mathbf{S}=\left[\begin{array}{ll}36 \% & 36 \%\end{array}\right]$. For an evaluation of the quality of hypersurface structures these minima were optimized freely. During the optimization the cell constants and angles showed only minor changes (see Table 2) and the interlayer distance $\mathrm{d}$ with $3.2-3.3 \AA$ reproduces very well the value obtained from the diffraction data. In addition, the geometry of the heptazine strands remained unaltered though they slightly tilt out of the $a b$ plane (see Fig. 9). After the optimization the minima on the hypersurface (Fig. 8) at $\mathbf{S}=[0 \% 24 \%], \mathbf{S}=[16 \% 12 \%]$ and $\mathbf{S}=[36 \% 36 \%]$ shift to $\mathbf{S}=[0 \% 22.8 \%], \mathbf{S}=[12.4 \% 7.2 \%]$ and $\mathbf{S}=[35.0 \% 37.2 \%]$, respectively. The small deviations demonstrate that the energy surface based on single point calculations (Fig. 8) reproduces the energetic situation in the structure of melon quite well. The deepest minimum occurs at $\mathbf{S}=\left[\begin{array}{lll}16 \% & 12 \%\end{array}\right]$ and is roughly one $\mathrm{kcal} \mathrm{mol}^{-1}$ lower in energy than the other two minima. 


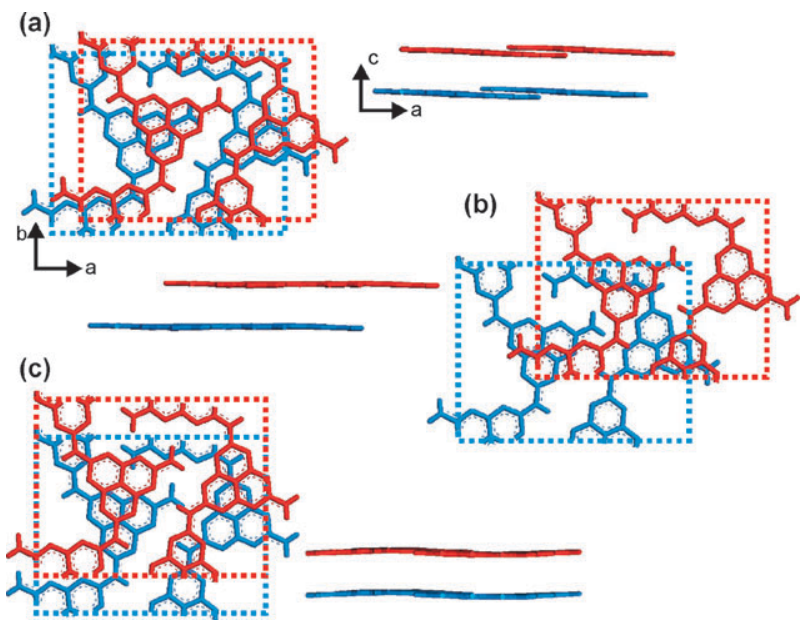

Fig. 9 Optimized structures with minimal energies at shift vectors (a) $\mathbf{S}=[12.4 \% 7.2 \%]$, (b) $\mathbf{S}=[35.0 \% 37.2 \%]$ and (c) $\mathbf{S}=[0.0 \% 22.8 \%]$. They correspond to the three minima on the energy hypersurface at $\mathbf{S}=[16 \% 12 \%], \mathbf{S}=[36 \% 35 \%]$ and $\mathbf{S}=[0 \% 24 \%]$ (compare Fig. 8 )

\section{Discussion}

In the following we will compare the results for the lateral arrangement in melon from the CP experiment and the force field calculations. To simplify this comparison in both cases the dark areas of Fig. 7 and 8 represent shift vectors of favored structures. It becomes clear that these two hypersurfaces show a similar profile. The only disagreement between the two methods can be identified for $\mathbf{S}=[50 \% 50 \%]=[8.4 \AA 0.4 \AA]$ which is favored by the NMR data but has an energy which is about $12 \mathrm{kcal} \mathrm{mol}^{-1}$ higher than the global minimum and is, thus, definitely disfavored from energetic considerations. Therefore, it was discarded as a reasonable lateral arrangement. A possible explanation for the contradictory preference of the NMR data for this structure can be found in the use of sum intensities of ${ }^{13} \mathrm{C}$ signals which had to be employed for the $\mathrm{CP}$ rate analysis. As we showed recently for homonuclear spindiffusion experiments, such overlapping signals can lead to a good agreement of experimental and calculated build-up curves even for incorrect structure models. ${ }^{63}$ The structure models discussed in the following however agree for the two employed methods (CP rates and energies) and thus represent authentic maxima and minima.

Both the NMR and the energy hypersurfaces favor shifting along the $b$-axis while the shift parameter for the $a$-axis remains zero (Fig. 7(b) and 8). The minimum for the force field energy is located at $\mathbf{S}=[0 \% 20 \%]=\left[\begin{array}{ll}0.0 \AA 2.6 \AA\end{array}\right]$ while for the CP NMR data it is found at $\mathbf{S}=[0 \% 50 \%]=[0.0 \AA$ $6.4 \AA]$. However, at about $\mathbf{S}=[0 \% 40 \%]=[0.0 \AA 5.1 \AA]$ in both hypersurfaces the values lie only slightly above the minima. Thus, for further discussion this shift vector is taken as a mean minimum (compare Fig. 7(b) and 8). The second region where both the NMR and energy hypersurface share minima is situated at $\mathbf{S}=[22 \% 5 \%]=[3.7 \AA 0.6 \AA]$. In this case the position of the minima is nearly identical for both hypersurfaces. Clearly disfavored in both hypersurfaces is the ecliptic arrangement with $\mathbf{S}=[0 \% 0 \%]$. Further light-colored and thus unfavored areas are found around $\mathbf{S}=[50 \% 0 \%]=$

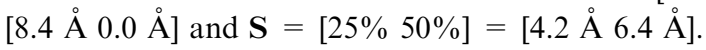

Fig. 10(a) and (b) show the structures of the two mean minima at $\mathbf{S}=[0 \% 40 \%]=[0.0 \AA 5.1 \AA]$ and $\mathbf{S}=[22 \% 5 \%]=$ $[3.7 \AA 0.6 \AA]$. Both reveal geometries where the heptazine units of adjacent layers are arranged in a staggered way. Fig. 10(c) and (d) depict the layer arrangement for two of the three mean maxima on the hypersurfaces at $\mathbf{S}=[50 \% 0 \%]$ $=\left[\begin{array}{llll}8.4 & \AA & 0.0 & \AA\end{array}\right]$ and $\mathbf{S}=\left[\begin{array}{lll}25 \% & 50 \%\end{array}\right]=\left[\begin{array}{llll}4.2 & \AA & 6.4 & \AA\end{array}\right]$. The ecliptic arrangement at $\mathbf{S}=\left[\begin{array}{lll}0 \% & 0 \%\end{array}\right]$ was omitted in Fig. 10 due to the perfect congruence of both layers. The structures displayed in Fig. 10(c) and (d) as well as the ecliptic arrangement have in common that at least two out of four heptazine units per unit cell are arranged in an ecliptic mode with adjacent layers. Thus, from both the minima and the maxima structure models it may be concluded that the preferred relative positions of the layers in melon are dominated by the purpose of obtaining as little overlap for the heptazine rings as possible in order to maximize the $\pi-\pi$ interactions.

\section{Conclusion}

In the presented publication we utilized a combination of solid-state NMR experiments and force field calculations to derive information about the stacking disorder of a layered material.

Based on a ${ }^{15} \mathrm{~N}$ spin-diffusion experiment the phase homogeneity of the sample could be established on the nanometre scale. Thus the two ${ }^{15} \mathrm{~N}$-signals for the $\mathrm{NH}$ and the $\mathrm{NH}_{2}$ group must arise from a reduction of the 2D layer symmetry by the $3 \mathrm{D}$ arrangement. For a further assignment of the overlapping resonances of the $\mathrm{CN}_{2}\left(\mathrm{NH}_{x}\right){ }^{13} \mathrm{C}$-signal we performed an $i \mathrm{DCP}$ experiment. We could differentiate between the $\mathrm{CN}_{2}\left(\mathrm{NH}_{2}\right)$ and the two $\mathrm{CN}_{2}(\mathrm{NH})$ signals. However, as one of the $\mathrm{CN}_{2}(\mathrm{NH})$ signals and the $\mathrm{CN}_{2}\left(\mathrm{NH}_{2}\right)$ signal overlap tightly a determination of their isolated intensities was not possible. This implied for the following $\mathrm{CP}$ experiment that the sum intensity of the $\mathrm{CN}_{2}\left(\mathrm{NH}_{x}\right)$ signals had to be employed wherefore only two $\mathrm{CP}$ build-up curves $\left(\mathrm{CN}_{3}\right.$ and $\mathrm{CN}_{2}\left(\mathrm{NH}_{x}\right)$ could be evaluated.

Table 2 Relevant parameters for the three minima of the energy hypersurface (Fig. 8): lateral shift vector $\left(\mathbf{S}_{\mathbf{0}}=[\Delta a \Delta b]\right)$ before optimization and cell parameters $(a, b, c, \alpha, \beta, \gamma)$, lateral shift vector $(\mathbf{S}=[\Delta a \Delta b])$, layer distance $(d)$ and force field energy $(E)$ for the optimized structures

\begin{tabular}{|c|c|c|c|c|c|c|c|c|c|c|}
\hline $\mathbf{S}_{0}[\%]$ & $a / \AA$ & $b / \AA$ & $c / \AA$ & $\alpha\left({ }^{\circ}\right)$ & $\beta\left(^{\circ}\right)$ & $\gamma\left({ }^{\circ}\right)$ & $\mathbf{S}[\%]$ & & $d / \AA$ & $E^{a} / \mathrm{kcal} \mathrm{mol}^{-1}$ \\
\hline 024 & 16.75 & 12.83 & 4.38 & 48.16 & 90.0 & 90.0 & 0.0 & 22.8 & 3.26 & -2.09 \\
\hline 1612 & 16.73 & 12.83 & 3.95 & 76.48 & 58.27 & 90.1 & 12.4 & 7.2 & 3.23 & -3.38 \\
\hline 3636 & 16.77 & 12.83 & 8.24 & 54.6 & 44.6 & 89.9 & 35.0 & 37.2 & 3.27 & -2.06 \\
\hline
\end{tabular}


(a)

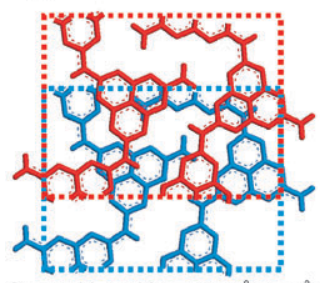

$\mathrm{S}=[0 \% 40 \%]=[0.0 \AA 6.7 \AA]$

(b)

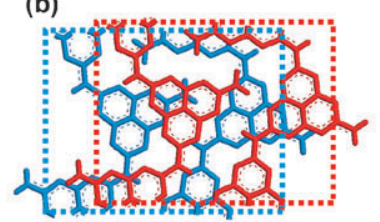

$\mathrm{S}=[22 \% 5 \%]=[3.7 \AA 0.6 \AA]$ (c)

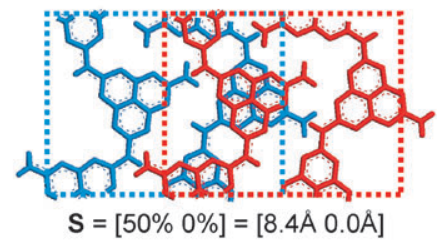

(d)

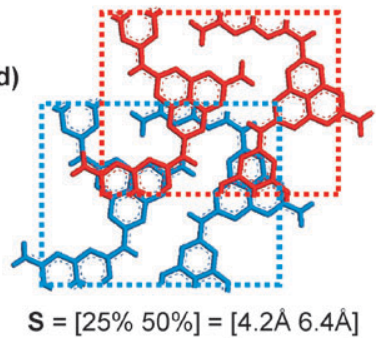

Fig. 10 Structures of the two favored positions on the mean hypersurface: (a) $\mathbf{S}=[0 \% 40 \%]$ and (b) $\mathbf{S}=[22 \% 5 \%]$. Layer arrangements for disfavored stacking scenarios: (c) at $\mathbf{S}=[50 \% 0 \%]$ and (d) $\mathbf{S}=[25 \% 50 \%]$.

For the $\mathrm{CP}$ experiment additionally an accurate knowledge of the position of the protons in melon was necessary. We determined the $\mathrm{NH}$ distances with the LG-CP experiment to $1.02 \AA$ for the $\mathrm{NH}$ group and to $1.04 \AA$ for the $\mathrm{NH}_{2}$ group. The $\mathrm{H}-\mathrm{N}-\mathrm{H}$ angle of the $\mathrm{NH}_{2}$ group was measured via the $\mathrm{H}-\mathrm{H}$ distance with the $\mathrm{R} 14_{2}^{6}$ pulse sequence. It was found to be $118.2^{\circ}$. These values were incorporated into the force field structures under retention of the torsion angles in order to generate structure models for the evaluation of the CP build-up curves. In addition, we computed the force field energies for structures with various lateral shifts along the $a$ and $b$ axis of the 2D structure. Thus, both methods gave information about preferred lateral arrangements of neighboring layers in melon. The comparison of the corresponding hypersurfaces revealed a very good agreement of these completely independent approaches. Structures with (partially) eclipsed arrangements gave maxima on the hypersurfaces and are thus disfavored. These are located at the shift vectors $\mathbf{S}=[0 \% 0 \%]$, $\mathbf{S}=[25 \% 50 \%]=[4.2 \AA 6.4 \AA]$ and around $\mathbf{S}=[50 \% 0 \%]=$ [8.4 $0.0 \AA$ A $]$. The lateral shifts preferred in both methods are situated at $\mathbf{S}=[20 \%-10 \%]=[3.3 \AA 0-1.3 \AA]$ and around $\mathbf{S}=[0 \% 40 \%]=[0.0 \AA 6.7 \AA]$. Both correspond to structures with a displacement for the heptazine rings in neighboring layers.

To conclude, we were able to obtain information about the $3 \mathrm{D}$ structure of melon although the material is disordered and no information can be gained from diffraction techniques. Due to the convincing results from solid-state NMR spectroscopy we are confident that this method will increasingly be utilized for the derivation of structure information in $\mathrm{C} / \mathrm{N}$ materials which are mostly semicrystalline or even amorphous.

\section{Acknowledgements}

We gratefully acknowledge financial support that was granted from the Deutsche Forschungsgemeinschaft (DFG) (projects

SE-1417/2-1 and SCH-377/12-2) as well as from the Fonds der chemischen Industrie (FCI).

\section{References}

1 A. Y. Liu and M. L. Cohen, Science, 1989, 245, 841-842.

2 C.-M. Sung and M. Sung, Mater. Chem. Phys., 1996, 43(1), 1-18.

3 E. Kroke and M. Schwarz, Coord. Chem. Rev., 2004, 248, 493-532.

4 I. Alves, G. Demazeau, B. Tanguy and F. Weill, Solid State Commun., 1999, 109, 697-701.

5 E. Kroke, M. Schwarz, E. Horvath-Bordon, P. Kroll, B. Noll and A. D. Norman, New J. Chem., 2002, 26, 508-512.

6 P. Kuhn, A. Forget, D. Su, A. Thomas and M. Antonietti, J. Am. Chem. Soc., 2008, 130(40), 13333-13337.

7 M. Doeblinger, B. V. Lotsch, J. Wack, J. Thun, J. Senker and W. Schnick, Chem. Commun., 2009, (12), 1541-1543.

8 J. Sehnert, K. Bärwinkel and J. Senker, J. Phys. Chem. B, 2007, 111, 10671-10680.

9 B. V. Lotsch, M. Döblinger, J. Sehnert, L. Seyfarth, J. Senker, O. Oeckler and W. Schnick, Chem.-Eur. J., 2007, 13, 4969-4980.

10 B. V. Lotsch and W. Schnick, Chem.-Eur. J., 2007, 13, 4956-4968.

11 B. Jürgens, E. Irran, J. Senker, P. Kroll, H. Müller and W. Schnick, J. Am. Chem. Soc., 2003, 125, 10288-10300.

12 B. V. Lotsch, J. Senker, W. Kockelmann and W. Schnick, J. Solid State Chem., 2003, 176, 180-191.

13 M. J. Bojdys, J.-O. Mueller, M. Antonietti and A. Thomas, Chem.-Eur. J., 2008, 14, 8177-8182.

14 A. Vinu, Adv. Funct. Mater., 2008, 18, 816-827.

15 M. Kawaguchi, S. Yagi and H. Enomoto, Carbon, 2004, 42, 345-350.

16 H. Sugimura, Y. Sato, N. Tajima and O. Takai, Surf. Coat. Technol., 2001, 142-144, 714-718.

17 H. Ito, T. Nozaki, A. Saikubo, N. Yamada, K. Kanda, M. Niibe and H. Saitoh, Thin Solid Films, 2008, 516, 6575-6579.

18 Y. F. Li, Z. Zhou and L. B. Wang, J. Chem. Phys., 2008, 129, 104703.

19 Z. B. Zhou, R. Q. Cui, Q. J. Pang, G. M. Hadi, Z. M. Ding and W. Y. Li, Sol. Energy Mater. Sol. Cells, 2002, 70, 487-493.

20 S. P. Lee, Sensors, 2008, 8, 1508-1518.

21 M. Deifallah, P. F. McMillan and F. Corà, J. Phys. Chem. C, 2008, 112, 5447-5453.

22 X. Wang, K. Maeda, A. Thomas, K. Takanabe, G. Xin, J. M. Carlsson, K. Domen and M. Antonietti, Nature Mater., 2009, 8(1), 76-80.

23 F. Goettmann, A. Fischer, M. Antonietti and A. Thomas, Angew. Chem., Int. Ed., 2006, 45, 4467-4471.

24 F. Goettmann, A. Thomas and M. Antonietti, Angew. Chem., Int. Ed., 2007, 46, 2717-2720.

25 F. Goettmann, A. Fischer, M. Antonietti and A. Thomas, New J. Chem., 2007, 31, 1455-1460.

26 M. Kim, S. Hwang and J.-S. Yu, J. Mater. Chem., 2007, 17, $1656-1659$.

27 H. Montigaud, B. Tanguy, G. Demazeau, I. Alves and S. Courjault, J. Mater. Sci., 2000, 35, 2547-2552.

28 H. Montigaud, B. Tanguy, G. Demazeau, I. Alves, M. Birot and J. Dunogues, Diamond Relat. Mater., 1999, 8, 1707-1710.

29 H. A. Ma, X. P. Jia, L. X. Chen, P. Zhu, W. L. Guo, X. B. Guo, Y. D. Wang, S. Q. Li, G. T. Zou, G. Zhang and P. Bex, J. Phys.: Condens. Matter, 2002, 14, 11269-11273.

30 T. Komatsu and T. Nakamura, J. Mater. Chem., 2001, 11, 474-478.

31 M. Kawaguchi and K. Nozaki, Chem. Mater., 1995, 7, 257-264.

32 E. G. Gillan, Chem. Mater., 2000, 12, 3906-3912.

33 M. Groenewolt and M. Antonietti, Adv. Mater., 2005, 17, $1789-1792$.

34 S. Matsumoto, E.-Q. Xie and F. Izumi, Diamond Relat. Mater., 1999, 8, 1175-1182.

35 B. V. Lotsch and W. Schnick, Chem. Mater., 2005, 17, 3976-3982.

36 L. Maya, D. R. Cole and E. W. Hagaman, J. Am. Ceram. Soc., 1991, 74, 1686-1688.

37 J. Kouvetakis, A. Bandari, M. Todd and B. Wilkens, Chem. Mater., 1994, 6, 811-814.

38 C. Wang, S. Yang and J. Zhang, J. Non-Cryst. Solids, 2008, 354, $1608-1614$. 
39 S. Muhl and J. M. Méndez, Diamond Relat. Mater., 1999, 8, 1809-1830.

40 L. Liu, D. Ma, H. Zheng, X. Li, M. Cheng and X. Bao, Microporous Mesoporous Mater., 2008, 110, 216-222.

41 Q. Guo, Y. Xie, X. Wang, S. Zhang, T. Hou and S. Lv, Chem. Commun., 2004, 26-27.

42 Z. Zhang, K. Leinenweber, M. Bauer, L. A. J. Garvie, P. F. McMillan and G. H. Wolf, J. Am. Chem. Soc., 2001, 123, 7788-7796.

43 T. Komatsu, J. Mater. Chem., 2001, 11, 802-805.

44 J. R. Holst and E. G. Gillan, J. Am. Chem. Soc., 2008, 130, 7373-7379.

45 A. C. Ferrari, S. E. Rodil and J. Robertson, Phys. Rev. B: Condens. Matter Mater. Phys., 2003, 67, 155306-9634.

46 L. Seyfarth and J. Senker, Phys. Chem. Chem. Phys., 2009, 11, $3522-3531$.

47 J. Liebig, Ann. Chem., 1834, 10, 1-47.

48 B. M. Fung, A. K. Khitrin and K. Ermolaev, J. Magn. Reson., 2000, 142, 97-101.

49 Y. Ishii, J. Chem. Phys., 2001, 114, 8473-8483.

50 S. Zhang, X. Wu and M. Mehring, Chem. Phys. Lett., 1990, 173, 481-484.

51 M. Bjerring and N. C. Nielsen, Chem. Phys. Lett., 2003, 382, 671-678.

52 B.-J. van Rossum, C. P. de Groot, V. Ladizhansky, S. Vega and H. J. M. de Groot, J. Am. Chem. Soc., 2000, 122, 3465-3472.
53 J. Becker, A. Comotti, R. Simonutti, P. Sozzani and K. Saalwächter, J. Phys. Chem. B, 2005, 109, 23285-23294.

54 M. H. Levitt, in Encyclopedia of Nuclear Magnetic Resonance, ed. D. M. Grant and R. K. Harris, John Wiley \& Sons, Ltd, Chichester, 2002, vol. 9, Advances in NMR, pp. 165-196.

55 M. Carravetta, A. Danquigny, S. Mamone, F. Cuda, O. G. Johannessen, I. Heinmaa, K. Panesar, R. Stern, M. C. Grossel, A. J. Horsewill, A. Samoson, M. Murata, Y. Murata, K. Komatsu and M. H. Levitt, Phys. Chem. Chem. Phys., 2007, 9, 4879-4894.

56 W. Kolodziejski and J. Klinowski, Chem. Rev., 2002, 102, 613-628.

57 M. Bak, J. T. Rasmussen and N. C. Nielsen, J. Magn. Reson., 2000, 147, 296-330.

58 The language of technical computing. MATLAB; Math Works Inc., 24 Prime Park Way, Natick, MA 01760-1500, Copyright 1984-2004.

59 Accelerys software inc., MS Modeling v4.0.0.0, Copyright 2005.

60 C. A. Fyfe, A. C. Diaz, H. Grondey, A. R. Lewis and H. Förster, J. Am. Chem. Soc., 2006, 128, 11860-11871.

61 R. S. Paton and J. M. Goodman, J. Chem. Inf. Model., 2009, 49(4), 944-955.

62 J. C. Osborn and P. York, J. Mol. Struct., 1999, 474(1-3), 43-47.

63 F. W. Karau, L. Seyfarth, O. Oeckler, J. Senker and W. Schnick, Chem.-Eur. J., 2007, 13, 6841-6852. 